\title{
Introduction to the Special Focus Column
}

\author{
Shibing Dai* and Peng Zhang \\ College of Architecture and Urban Planning, Tongji University, Shanghai, China \\ * Corresponding Author: daishibing@tongji.edu.cn
}

We are delighted to act as guest editors for the Special Focus Column entitled 'Technology for Conservation and Restoration of Built Heritage', which opens the third volume of Built Heritage. Built Heritage is the first international journal published in English on heritage conservation in China, and one of its objectives is to share the latest research results from China with the rest of the world. Our main purpose with this column is to provide a platform to promote exchanges about specific issues related to material science conservation.

China's architectural heritage is multifaceted. With traditional architecture, styles and techniques vary from region to region owing to locally available resources related to climate, geology, and ethnicity. In addition to traditional Chinese architecture, a variety of Westerninfluenced architecture exists (e.g. modern Chinese architecture since the mid- $19^{\text {th }}$ century), often with a mixture of Chinese and Western architectural styles, decorative elements, and techniques. Our contention is that both threads-traditional and modern-require specific material conservation methods; those methods need to be compatible with the buildings' characteristics and also allow their continued use in the future.

The Principles for the Conservation of Heritage Sites in China (revised by ICOMOS China and approved by the State Administration of Cultural Heritage in 2015) provide integrated, methodological approaches for conservation and management in compliance with existing legislation of the People's Republic of China. However, conservation of China's built heritage is endangered by inadequate technological methods, lack of academically trained restoration practitioners and skilled craftsmen, and a deficiency of knowledge of historical structures and building materials.

To bridge the gap between theory and practice, various institutions and organisations have worked together in recent years in China to confront numerous challenges. Among them, the work of the Tongji University Architectural Conservation Laboratory (Tongji-ACL) in Shanghai deserves particular recognition. It was founded in 2008 as a research and teaching laboratory of the College of Architecture and Urban Planning of Tongji University. It comprises specialised laboratories involved in conserving earth, wood, stone (natural and manmade), and plaster structures of heritage architecture.

In accordance with international best practices in conservation, Tongji-ACL is developing and implementing conservation technical solutions for the built heritage in a rich variety of projects of architectural restoration. TongjiACL also serves as a platform for international academic exchanges: one of the latest examples of exchange initiatives it has promoted is the International Conference on Conservation Technology of Built Heritage (ICCTBH), which successfully took place on 6-9 June 2018 in Shanghai. The articles for this Special Focus Column were selected from the presentations made at that conference and subsequent constructive discussions.

Peng Zhang and Yijiao Yang's article 'Transplantation to Localisation: The Importation of Western Structural Technologies in Modern Shanghai Architecture Based on a Study of the Bund Buildings, 1843-1943' constituted an architectural survey and literature investigation of the Bund buildings in Shanghai. The article illustrates the evolution of modern structural technologies in Shanghai. It is a valuable documentation and study resource that can inform future conservation initiatives in this world-class, famous historic area.

Non-destructive tests have been increasingly used for historic buildings: they have been applied for pre-restoration investigations and method statement specifications; they have also been utilised as useful monitoring tools to evaluate the effectiveness of eventual interventions. Chung Wan Wong's article 'Applications of Non-Destructive Tests for Diagnosis of Heritage Buildings: Case Studies from Singapore and Malaysia' describes common methods employed in projects in Singapore and Malaysia; the methods include infrared thermography, ground-penetrating radar, microwave moisture tomography, and ultrasonic 
pulse echo tomography. Case studies demonstrate the applications of various techniques to identify hidden details, detect moisture, and locate defects and deterioration.

Traditional plasters have traditionally played an important role as a protective and decorative outer layer; however, they can be modernised to fulfil both technical and aesthetic functions for the modern use of the built heritage, such as allowing modern habitation in historic structures. Tanja Dettmering's paper contributes to our understanding of traditional and modernised use of lime plaster in Germany; it indicates how that material has been incorporated for sustainable conservation. The paper provides a constructive reflection about how traditional Chinese lime technology may be further developed to be historically and technically compatible with modern conservation practice.

Shibing Dai and Yan Zhong's article 'Sacrificial Protection for Architectural Heritage Conservation and Preliminary Approaches to Restore Historic Fair-Faced Brick Façade in China' starts with a summary of the sacrificial protection and technical options in Europe with respect to architectural surface conservation. The concept of sacrificial protection did not originate in Chinese conservation practices; however, it has gradually been adopted by Chinese conservation administrators, architects, and practitioners to deal with conscious aesthetic modification for sustainable conservation and revitalisation of the architectural heritage. Two case studies show those preliminary approaches to restore historic fair-faced brick façades in China.

We would like to thank the authors of all the articles as well as the editorial team of Built Heritage for their support in the publication of this Special Focus Column, which aims to enhance the relevance of 'dry' technical issues of conservation. We also thank the reviewers for their helpful comments and suggestions. 